OPEN ACCESS

Edited by:

Eric C. J. Oliver,

Dalhousie University, Canada

Reviewed by:

Pengfei Lin,

Institute of Atmospheric Physics

(CAS), China

Yizhen Li,

Woods Hole Oceanographic

Institution, United States

${ }^{*}$ Correspondence:

Melanie R. Fewings

melanie.fewings@oregonstate.edu

Specialty section:

This article was submitted to Global Change and the Future Ocean,

a section of the journal

Frontiers in Marine Science

Received: 18 May 2019 Accepted: 27 August 2019

Published: 04 October 2019

Citation:

Fewings MR and Brown KS (2019) Regional Structure in the Marine Heat Wave of Summer 2015 Off the Western United States.

Front. Mar. Sci. 6:564. doi: 10.3389/fmars.2019.00564

\section{Regional Structure in the Marine Heat Wave of Summer 2015 Off the Western United States}

\author{
Melanie R. Fewings ${ }^{1 *}$ and Kevin S. Brown ${ }^{2,3}$ \\ ${ }^{1}$ College of Earth, Ocean, and Atmospheric Sciences, Oregon State University, Corvallis, OR, United States, ${ }^{2}$ Department of \\ Pharmaceutical Sciences, College of Pharmacy, Oregon State University, Corvallis, OR, United States, ${ }^{3}$ School of Chemical, \\ Biological, and Environmental Engineering, College of Engineering, Oregon State University, Corvallis, OR, United States
}

One of the largest warm water anomalies (marine heat waves [MHWs]) ever recorded occurred in the northeast Pacific during 2014-2016. This MHW was caused by large-scale atmospheric ridging and affected fisheries and ecosystems from Alaska through California, including a bloom of toxic algae spanning the entire coastline. Regional variations in MHW severity are common along coastlines worldwide but are generally unexplained. During the 2014-16 MHW, the summertime sea-surface temperature (SST) anomalies were often stronger along the southern half of the coastline off the western continental United States. The reason for this north-south difference in severity of the MHW within the California Current System (CCS) has remained unclear. The scientific community's lack of understanding of regional variations within MHWs prevents accurate prediction of SST anomalies and resulting ecological and economic impacts. We show the north-south difference in SST anomalies was due to a known wind pattern determined by the coastline shape. The wind anomalies in summer have a quasi-dipole structure: the northern lobe extends southwest from Washington/Oregon, and the southern lobe has opposite sign and extends south from Cape Mendocino in a triangle due to a hydraulic expansion fan in the marine boundary layer. The alternating wind intensifications and relaxations typically last several days. However, the large-scale ridging during the MHW was associated with unusual persistence in this pattern: in summer 2015 a single wind relaxation in the southern lobe lasted 2 weeks. These wind anomalies induce changes in SST, likely via changes in wind-driven vertical entrainment of cold water from below the mixed layer, and mixed-layer shoaling; the net air-sea heat flux anomaly is small. The July 2015 wind relaxation persisted so long that the changes in SST exceeded pre-existing SST variations. The resulting SST anomalies have a dipole pattern similar to the wind anomalies. These dipole SST anomalies explain the north-south asymmetry in the CCS MHW. We suggest that during future persistent ridging events, the SST anomalies off the western continental U.S. will develop a north-south split structure similar to July 2015.

Keywords: marine heat wave, heat budget, mixed layer, air-sea flux, California Current, 2015, coastal wind patterns, upwelling system 


\section{INTRODUCTION}

\subsection{The Marine Heat Wave Off Western North America in 2014-16}

One of the largest warm water anomalies (marine heat waves [MHWs]) ever recorded in the northeast Pacific occurred during 2014-2016. During this MHW, sea-surface temperatures (SSTs) in the Gulf of Alaska (GoA) were $\sim 3^{\circ} \mathrm{C}$ higher than normal (e.g., Figure 1A) for prolonged periods. This $\mathrm{MHW}$ in the GoA was caused by large-scale atmospheric high pressure ridging over the eastern North Pacific and western North America (Bond et al., 2015; Hartmann, 2015) and associated with record-low sea level along the coast of Alaska during winter 2013-2014 (Wang et al., 2019). The GoA MHW became known in the popular press as "the Blob" (Bond et al., 2015). By 2015, the MHW extended along the coast of the western continental United States (U.S.) (Gentemann et al., 2016; Zaba and Rudnick, 2016) and later to Baja California in Mexico (Robinson, 2016; Myers et al., 2018). The MHW persisted over multiple years due to atmospheric teleconnections from the tropics (Di Lorenzo and Mantua, 2016; Liang et al., 2017; Tseng et al., 2017). This prolonged MHW in the northeast Pacific eventually overlapped with the 2015-16 El Niño (Jacox et al., 2016; Zaba and Rudnick, 2016; Chao et al., 2017; Zaba et al., 2018), though the impacts of the El Niño were weaker than usual along western North America (Barnard et al., 2017; Frischknecht et al., 2017; Paek et al., 2017). This MHW caused major damage to economically important fisheries and other ecosystems from Alaska through California associated with species shifts (Whitney, 2015; Cavole et al., 2016; Auth et al., 2017; Daly et al., 2017; Peterson et al., 2017; Du and Peterson, 2018; Gomez-Ocampo et al., 2018; Kahru et al., 2018) and an unprecedentedly large bloom of toxic algae that spanned the entire coastline (McCabe et al., 2016).

Along the coast of the western continental U.S., the MHW developed an unexplained "split" structure in summer 2015. The monthly sea-surface temperature (SST) anomalies were generally much stronger along the southern half of the continental U.S. coastline, i.e., California, than the northern half, Washington and Oregon (Gentemann et al., 2016). When and where upwellingfavorable winds were present along the coast, those winds mitigated the SST anomalies, particularly in the spring upwelling season; in summer and early fall the winds were more variable and the warm SST anomalies frequently returned, particularly along the southern part of the coast. This north-south difference was so strong by July 2015 that the MHW split into two parts, one in the GoA and one extending from central California to Baja California (Figure 1B). The two warm anomalies were separated by a "cool corridor" (Gentemann et al., 2016). This split structure was described as Phase III of the development of the MHW (Peterson et al., 2016) and the split was reported in the journal Science as "flummoxing" climate experts (Kintisch, 2015).

The reason for this split in the MHW has to date remained unclear. The strong regional variation in SST anomalies within the 2014-2016 northeast Pacific MHW is consistent with regionspecific variations worldwide in (i) the frequency of MHWs (Scannell et al., 2016), (ii) the intensity and duration of MHWs (Oliver et al., 2018), (iii) the rate of change of the number of days with extremely cold or warm SST along the coast (Lima and Wethey, 2012), and (iv) the physical forcing of MHWs (Holbrook et al., 2019). The scientific community's lack of understanding of the causes of these regional variations within MHWs, especially events not associated with El Niño, prevents accurate prediction of MHWs and the resulting economic and ecological impacts (Jacox et al., 2019). Here, we link the regional variations in the northeast Pacific MHW to a characteristic regional wind pattern that also occurs during "normal" years but was unusually persistent during the $2015 \mathrm{MHW}$.

\subsection{Typical Regional Wind Patterns Over the California Current System in Summer}

The mean wind pattern over the California Current System (CCS) in summer consists of equatorward wind everywhere along the coast of the western continental U.S. (e.g., Figure 2A). This prevailing wind is driven by the pressure gradient between
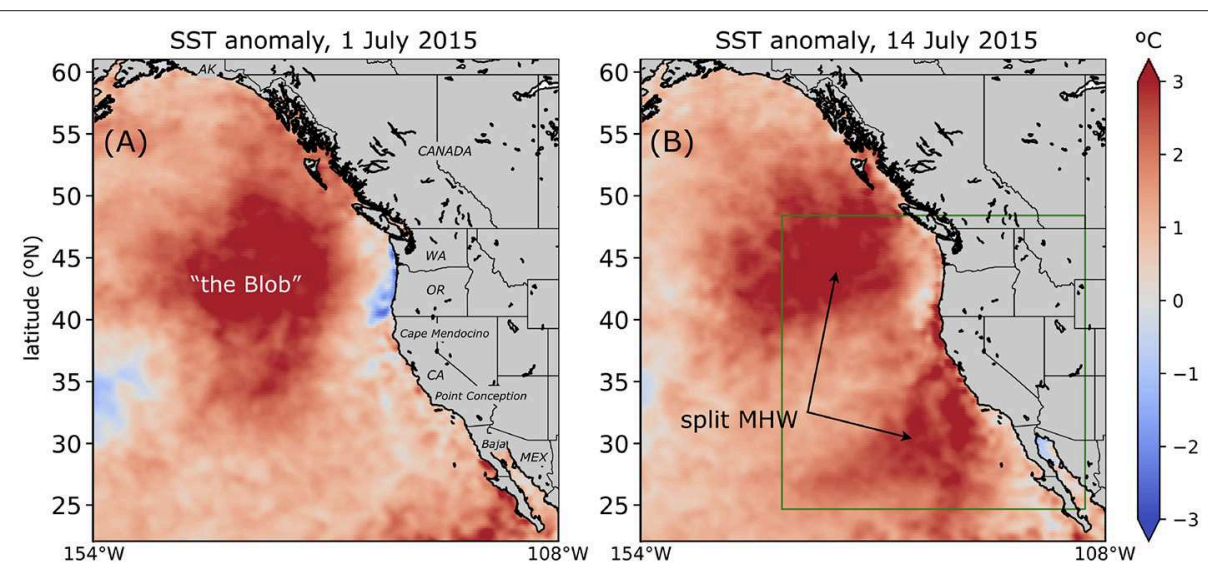

FIGURE 1 | SST anomalies before and after the formation of the July 2015 split MHW: (A) 1 July 2015 and (B) 14 July. The SST anomaly at each location is calculated relative to a daily long-term climatology using the CMC SST product (section 2.2). The vertical axis limits are 22 and $61^{\circ} \mathrm{N}$. Green rectangle in (B) shows area covered by Figures 2, 4. 

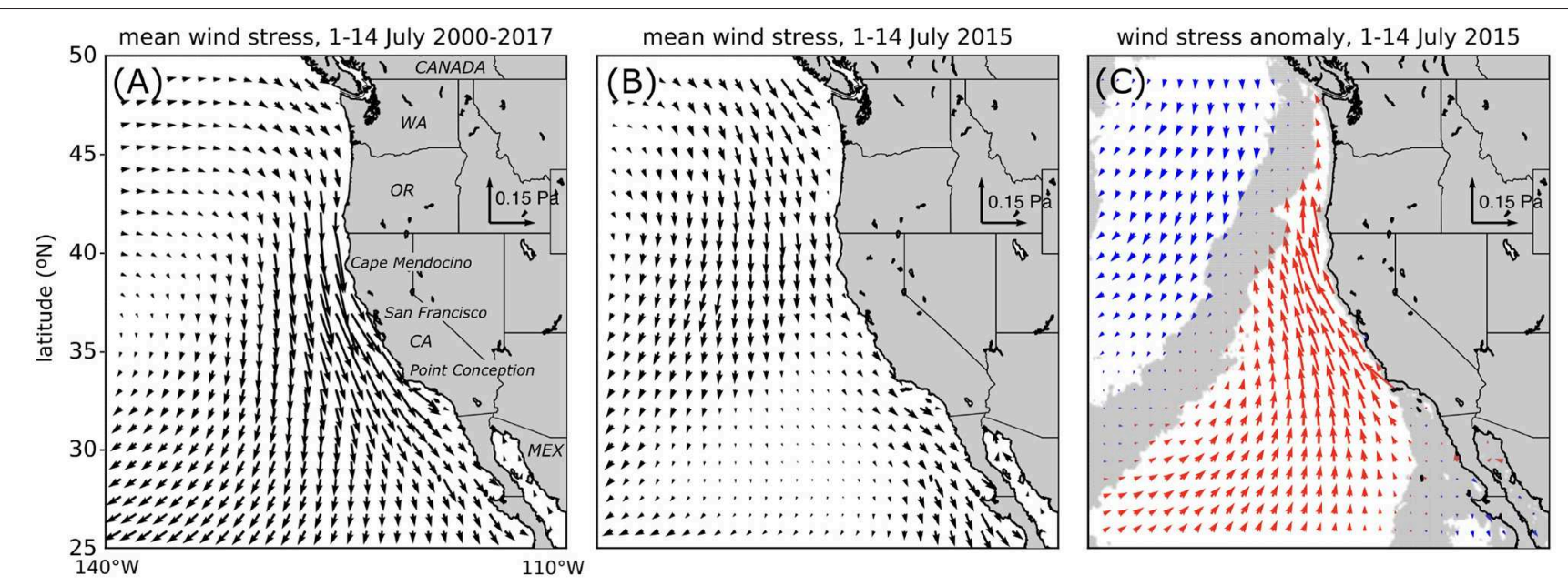

FIGURE 2 | 1-14 July wind stress climatological mean, 2015 mean, and anomaly preceding the development of the split MHW. (A) Mean wind stress during 1-14 July 2000-2017. Arrows indicate the wind stress direction in oceanographic convention, i.e., the direction the wind is blowing toward. (B) Mean wind stress during 1-14 July 2015. (C) Time-mean wind stress anomaly, relative to the long-term mean in (A), during 1-14 July 2015. (C) is equal to (B) minus (A). In (C), vectors are colored red if the northward component of the wind stress vector anomaly is positive, which along the coast corresponds to wind relaxation, and blue if the northward component of the wind stress anomaly is negative. Gray shading in (C) indicates anomaly is not significantly different from zero at the $95 \%$ confidence level (section 3.2).

the offshore subtropical North Pacific High atmospheric pressure system and the desert heat low pressure area over the southwest U.S. (e.g., Neiburger et al., 1961; Halliwell and Allen, 1987); see the introduction of Fewings et al. (2016) for a brief review of the related literature. The wind direction is polarized along the coast due to the influence of the coastal mountains, except near gaps, such as San Francisco Bay. Off California, the strength of the wind is intensified for several hundred $\mathrm{km}$ offshore by hydraulic effects of the large-scale bend in the coastline at Cape Mendocino (Figure 2A) (Edwards et al., 2002).

Superimposed on this mean wind pattern are strong wind fluctuations on time scales of days. The synoptic, or weatherband, fluctuations in the along-coast wind velocity have amplitudes comparable to the mean in the northern half of the system and greater than the mean in the southern half of the system (Halliwell and Allen, 1987). As a result, at any location along the coast, the along-coast wind velocity frequently weakens to near zero ("relaxes") or even reverses direction for several days (Bond et al., 1996; Mass and Bond, 1996; Nuss et al., 2000). Interspersed with these wind relaxations and reversals are wind intensification events where the wind is upwellingfavorable and stronger than the mean (Halliwell and Allen, 1987; Taylor et al., 2008). The wind relaxations or reversals, and the intervening intensifications, are forced by groups of three related air pressure anomalies: (1) mid-level troughing over Washington and Oregon is followed by (2) mid-level ridging as Rossby waves or extra-tropical cyclones are advected eastward on the jet stream (Halliwell and Allen, 1987; Bond et al., 1996; Mass and Bond, 1996; Bane et al., 2005, 2007). This ridging causes an anticyclonic circulation that advects low-pressure air offshore from over the desert in the southwestern U.S., causing (3) low pressure at sea level off California (Nuss, 2007). The resulting fluctuations in the along-coast pressure gradient along the coast at sea level drive a coherent pattern of wind intensifications and relaxations that accompanies the three air pressure anomalies: (1) wind relaxation or reversal off Oregon/Northern California (Halliwell and Allen, 1987; Bane et al., 2005, 2007) accompanied by intense upwelling-favorable winds off central California, then (2) intensified upwelling-favorable winds off central California (Taylor et al., 2008), then (3) wind relaxation (Melton et al., 2009) or rarer reversal (Nuss, 2007) off central California accompanied by intensified winds off Oregon/Northern California (Fewings et al., 2016). This coherent cycle of wind relaxations and intensifications tends to repeat every $\sim 10-20$ days throughout the summer, with individual wind relaxation or intensification stages (1)-(3) each lasting 2-5 days (Fewings et al., 2016).

These wind fluctuations can be understood as part of a regional quasi-dipole wind pattern. The pattern extends $1600 \mathrm{~km}$ along the coast, from Washington past California, and $\sim 600 \mathrm{~km}$ offshore: when upwelling-favorable winds are enhanced over the north part of the CCS, the winds tend to be reduced (relaxed) over the south part of the CCS, and vice versa (Fewings et al., 2016). We refer to stages (1) and (3) described above as the "northern relaxation" and "southern relaxation" phases, respectively, of the wind quasi-dipole pattern. One way to quantify the quasidipole wind pattern is with Hilbert Empirical Orthogonal Function (HEOF) analysis (section 3.3). There is some poleward propagation in the wind fluctuations, which leads to the need for HEOF analysis instead of standard EOF analysis (Fewings, 2017). The propagation is partly due to east-west propagating pressure anomalies crossing an angled coastline, resulting in apparent along-coast propagation [there is also propagation of coastal-trapped wind reversals due to smaller-scale dynamics within $\sim 10$ s of $\mathrm{km}$ of the coast (Nuss et al., 2000), but trapped 
reversals are not the focus of this study]. The leading HEOF of along-coast wind velocity (HEOF 1) along the U.S. West Coast for May-August 1981-2009 captures 60\% of the variance on time scales of days to months (Fewings, 2017). The spatial phase of HEOF 1 captures the quasi-dipole wind pattern, with wind fluctuations off Washington and Oregon $\sim 140^{\circ}$ out of phase with wind fluctuations at Point Conception on average. The "southern relaxation" wind anomaly stage described above is well represented by the positive phase of HEOF 1: when HEOF 1 is composited over an index of known wind relaxations from NOAA buoys (Melton et al., 2009), the southern relaxations and opposite northern relaxation phase both appear in the composites (Fewings, 2017). Therefore, zero crossings of the HEOF are associated with the onset of local wind relaxation off central California (Fewings, 2017). In a typical summer, the wind quasi-dipole oscillation cycles every $\sim 10-12$ days, with the southern and northern relaxation states each lasting $\sim 2-5$ days (Fewings et al., 2016; Fewings, 2017).

The offshore extent and spatial shape of the quasi-dipole wind structure is determined by both the atmospheric pressure patterns and the shape of the coastline. The prevailing wind in the marine boundary layer off California in summer has transcritical Froude number (Rogerson, 1999) and becomes intensified downstream of the large-scale bend in California at Cape Mendocino due to a hydraulic expansion fan extending hundreds of $\mathrm{km}$ to the southwest (Edwards et al., 2002). This gives a triangular shape to the region of enhanced winds off California during stage (1) above, with the apex near Cape Mendocino. The wind in this triangular area weakens during stage (3). This creates a negative wind velocity anomaly, relative to the summer mean, with the same triangle shape as the "missing" expansion fan (Fewings et al., 2016). Therefore, the wind quasi-dipole is not only a "coastal" mode, but also has regional-scale impacts hundreds of $\mathrm{km}$ offshore. This wind quasi-dipole pattern is endemic to the CCS eastern boundary upwelling system. The wind dipole and its triangular southern lobe of coherent wind fluctuations off California results from the particular shape of the coastline of western North America: a large bend in the coastline is located near the central latitude of the dominant atmospheric pressure gradient forcing pattern. A key point for this study is that stage (3), wind relaxation off California, occurs during atmospheric ridging (Nuss, 2007; Fewings et al., 2016).

\subsection{SST and Air-Sea Heat Flux Anomalies Associated With Typical CCS Wind Patterns}

The regional wind relaxations and intensifications described above are accompanied by changes in SST. In particular, the wind quasi-dipole pattern is associated with dipole anomalies in SST trends (Flynn et al., 2017). During a typical "southern relaxation," the SST anomaly off central California increases by $\sim 0.25-0.5^{\circ} \mathrm{C}$ for several days, with a lag of $\sim 2$ days following the onset of the wind relaxation. However, the actual SST anomaly usually remains negative or near zero because southern wind relaxations are typically preceded by wind intensifications, i.e., the opposite phase of the quasi-dipole, and those wind intensifications create negative SST anomalies (Flynn et al., 2017). The increase in SST anomaly during the following wind relaxation then restores the SST from a negative anomaly to near the climatological value (zero anomaly). During the subset of southern wind relaxations driven by stronger pressure anomalies, which involve coastal wind reversal rather than just weak wind, warm SST anomalies $\sim 1^{\circ} \mathrm{C}$ develop off central California (Juliano et al., 2019).

During the typical regional wind relaxations, the net air-sea heat flux anomalies are too small to explain the SST warming trend off California (Flynn et al., 2017). There is not a strong positive air-sea heat flux anomaly during the southern relaxation events because the events are accompanied by reduced shortwave radiation, due to increased cloudiness. A scaling analysis of other terms in the 3-D heat budget indicates that offshore of the $\sim 200$ $\mathrm{km}$ wide coastal upwelling region, the warming in SST during the wind relaxations off California is likely from shoaling of the ocean surface mixed layer (ML) due to reduced wind-driven vertical mixing and Ekman pumping (Flynn et al., 2017). The ML can them warm because the (climatological) air-sea heat flux heats a shallower ML, and because entrainment at the base of the ML is presumably reduced during wind relaxations.

\subsection{This Study}

The characteristic quasi-dipole wind pattern recently described off the western U.S. (Fewings et al., 2016; Fewings, 2017), and the changes in SST typically associated with that wind pattern (Flynn et al., 2017; Juliano et al., 2019), discussed above, have not been considered as a possible cause of regional variation in SST anomalies during MHWs. Here, we show that the splitting of the MHW in summer 2015 (Figure 1B) can be explained by the existence of this wind dipole pattern. We suggest that regional variations within the $\mathrm{MHW}$ occurred because the unusual atmospheric ridging that caused the northeast Pacific MHW also triggered the wind dipole pattern characteristic of the CCS to persist for an unusually long time in its southern relaxation state. Together with the preexisting "background" warm SST anomaly in the GoA, a wind-forced dipole-like SST anomaly along the western continental U.S. explains the split MHW pattern described in section 1.1.

We focus on 1-14 July 2015 as a clear case of the MHW developing a split structure. We analyze a heat budget for the ocean surface mixed layer to understand the cause of SST changes during the development of the split MHW. Many studies of the causes, spatial pattern, and timing of the northeast Pacific MHW of 2014-2016 focus on monthly anomalies (e.g., Bond et al., 2015; Di Lorenzo and Mantua, 2016; Gentemann et al., 2016; Chao et al., 2017), but those anomalies can be due to the presence of a few strong anomalies, or even a single anomaly, on synoptic time scales. Our study relates the SST variability to a wind forcing pattern that normally has a time scale of days, but during summer 2015 lasted for 2 weeks. This anomaly would be blurred in an analysis based on monthly averages. We use HEOF analysis (Fewings, 2017) to analyze scatterometer winds from RapidSCAT on the International Space Station and other satellites during summer 2000-2017, placing the 2014-2016 wind 
anomalies in the context of the typical wind patterns previously described for the region.

\section{DATA}

\subsection{Satellite Ocean Vector Wind Data}

We use L2 ocean vector wind swath data to analyze wind stress and wind velocity along the coast. Reanalysis wind fields are inaccurate within $\sim 2$ grid cells of the coast (Wallcraft et al., 2009), especially in regions with hydraulic expansion fans, such as our study area (Perlin et al., 2004). In particular, reanalysis winds poorly represent the wind intensifications and relaxations in this region (Fewings et al., 2016). Another advantage of scatterometer-only winds over reanalysis winds for this study is that effects of SST-stress interaction (e.g., Small et al., 2008) are intrinsically included in scatterometer wind data, whereas reanalyses enforce prescribed planetary boundary layer physics parameterizations.

The satellite ocean vector wind data used in this work are from three satellite microwave scatterometer missions: QuikSCAT on SeaWinds during 2001-2009 (Fore et al., 2014), RapidSCAT on the International Space Station (ISS) during 2014-2016 (RapidScat Project, 2016), and ASCAT on Metop-A during 2010-2019 (Verhoef et al., 2012; Verhoef and Stoffelen, 2013). QuikSCAT was, and ASCAT is, flown on a sun-synchronous, polar-orbiting satellite, providing nearly global coverage approximately twice daily. The QuikSCAT overpasses are at $\sim 6: 00$ am and 6:00 pm local time. The ASCAT overpasses are at $\sim 10: 00$ a.m. and 10:00 p.m. local time. In contrast, the ISS is not in a polar orbit, so the data coverage from RapidSCAT is restricted to $\sim 61^{\circ} \mathrm{N}$ to $61^{\circ} \mathrm{S}$, and the timing of swath overpasses is distributed more widely throughout the day than for the polar orbiting satellites. All three data sets are in the form of swaths, which are $1,800 \mathrm{~km}$ wide for QuikSCAT, $1100 \mathrm{~km}$ wide for RapidSCAT, and 2 parallel 512-km wide swaths with a 737-km wide "nadir gap" in between for ASCAT. The data are available as individual swath orbit files: QuikSCAT L2B v3.1 at https://podaac.jpl.nasa.gov/dataset/QSCAT_LEVEL_2B_OWV_ COMP_12_LCR_3.1; RapidSCAT L2B Climate v1.0 at https:// podaac.jpl.nasa.gov/dataset/RSCAT_LEVEL_2B_OWV_CLIM_ 12_V1; and ASCATA L2 Coastal PODAAC-ASOP2-12C01 at https://podaac.jpl.nasa.gov/dataset/ASCATA-L2-Coastal. The effective spatial resolution is $\sim 40 \mathrm{~km}$ for QuikSCAT (SeaPAC, 2016) and RapidSCAT (RapidScat Project, 2016), and $\sim 25 \mathrm{~km}$ for ASCAT (KNMI, 2010; Verhoef and Stoffelen, 2013).

The L2 scatterometer data are provided as equivalent neutral 10 -m wind velocity estimates on an irregular but $\sim 12.5-\mathrm{km}$ spaced "swath grid." High-quality data are available during both clear and cloudy conditions, and even during moderate rain, although rain is rare in our study area in summer.

\subsection{SST and Air-Sea Heat Fluxes}

We use the Canada Meteorological Center (CMC) $0.2^{\circ}$ SST product available at https://podaac.jpl.nasa.gov/dataset/CMC0. 2deg-CMC-L4-GLOB-v2.0 from the Group for High Resolution Sea Surface Temperature. The SST is available with daily temporal resolution and $0.2^{\circ} \mathrm{C}$ spatial resolution from 19912017. The product merges infrared and microwave data from multiple satellites and buoy and ship data to form a "Level 4" gapfree SST analysis (Brasnett, 2008; Canada Meteorological Center, 2012).

For latent and sensible air-sea heat fluxes, we use the OAFlux products (oaflux.whoi.edu). OAFlux provides objectively analyzed estimates of latent and sensible turbulent air-sea fluxes daily from 1958-present with global coverage on a $1^{\circ}$ grid (Yu and Weller, 2007; Yu et al., 2008). The SST used to estimate those fluxes is available on the same grid. The results presented below are similar if we instead use the SeaFlux product (Clayson et al., 2016) for latent and sensible air-sea heat fluxes (see Appendix in Supplementary Material). For radiative fluxes, we use the downwelling and upwelling shortwave and longwave radiative fluxes from CERES (Clouds and the Earth's Radiant Energy System, http://ceres.larc.nasa.gov).

\section{METHODS}

\subsection{Wind Stress: Calculating, Gridding, and Averaging}

We calculated vector wind stress $\vec{\tau}$ using the COARE v3.5 neutral-stability bulk algorithm (Edson et al., 2013) for each L2 swath in swath coordinates, as in Fewings et al. (2016). The wind velocity and vector wind stress were then gridded onto a $0.1 \times 0.1^{\circ}$ latitude-longitude grid using linear interpolation. The various angles at which individual satellite swaths cross the coast result in some locations very near the coast having more data from morning than evening satellite passes or vice versa. To avoid biases from the diurnal cycle when calculating means over several days or weeks (section 3.2), we processed the L2 swath data for morning and evening passes separately, as in Fewings et al. (2016): taking the mean of morning passes and separately taking the mean of evening passes, then calculating the mean of the morning and evening results.

\subsection{Calculating Climatologies, Means, and Anomalies}

For SST, we calculated a climatology using daily means for 1 July or 14 July $2000-2017$. For vector wind stress and for air-sea heat flux components, we calculated climatologies as the mean over the 2-week period 1-14 July 2000-2017. We then calculated anomalies relative to those climatologies. For the wind stress climatology, we used QuikSCAT and ASCAT, but not RapidSCAT, to avoid double-weighting the 2014-2016 time period. For the wind stress anomaly in 2015, we used both ASCAT and RapidSCAT to increase the number of overpasses available for calculating the anomaly.

To determine statistical significance of the anomalies, at each location we tested the anomaly (e.g., mean northward component of wind stress vector anomaly during 1-14 July 2015) against a mean anomaly of zero using a one-sample $t$-test, separately for ascending and descending passes. We combined the ascending and descending $p$-values at each location following Fisher (1992) and corrected for multiple hypothesis testing following Benjamini and Hochberg (1995). This combined, corrected $p$-value was then compared to 0.05 to determine where 
the anomaly value was significantly different from zero at the $95 \%$ confidence level.

\subsection{Hilbert EOFs}

As a tool for capturing the synoptic-scale wind velocity anomalies, we used the Hilbert Empirical Orthogonal Function (HEOF) analysis method (e.g., Hannachi et al., 2007). This modification of standard EOF analysis is necessary to study the wind relaxations because standard EOF analysis is only designed to handle stationary patterns, but the wind relaxations propagate in space and time (Fewings, 2017). In standard EOF analysis, any propagating fluctuations are split between two EOFs that are not statistically separate and should not be considered independently. In contrast, the same propagating fluctuations can be captured by a single HEOF. The HEOF calculation involves adding an existing time series to $i$ times a new time series based on the Fourier coefficients of the original, but constructed so that each frequency component is phase-shifted by $90^{\circ}$, where $i=\sqrt{-1}$. Timedomain EOFs are then calculated from the resulting complex time series following the usual EOF method but allowing for complex values. A more detailed review of the steps, including scaling and tapering, based on previous literature is available in Fewings (2017). The resulting HEOFs are complex, so each mode has both a spatial and temporal amplitude and, unlike in regular EOF analysis, a spatial and temporal phase. A modification of the above methods to calculate HEOFs from time series with gaps (in this case, the "gaps" between individual summers) is described in Fewings (2017); the method involves taking the Hilbert transform of the summer time series for each year separately, then joining the transformed time series together to form a single time series for all years, then proceeding with the typical steps of a complex EOF analysis in the time domain. Here, we use HEOF 1 as an index of the wind forcing state over the CCS to identify relaxations.

\subsection{Ocean Surface Mixed Layer Heat Budget}

We calculate a 1-dimensional (1-D, vertical) heat anomaly budget for the mixed layer using the same method as Flynn et al. (2017). The time-integrated heat budget anomaly equation can be written

$$
S S T^{\prime}(t)-S_{S} T^{\prime}\left(t_{0}\right)-\int_{t_{0}}^{t} \frac{Q_{n e t}^{\prime}}{\rho_{0} c_{p} h} d t=\int_{t_{0}}^{t} R d t
$$

where $S S T^{\prime}$ is the SST anomaly relative to climatology; $t$ is time and $t_{0}$ is the initial time (here, $t_{0}=1$ July 2015); $Q_{\text {net }}^{\prime}$ is the anomaly in net air-sea heat flux, relative to climatology, with positive indicating anomalous ocean warming (or less cooling than in the climatology); $\rho_{0}$ is a reference density of seawater; $c_{p}$ is the specific heat capacity of seawater; and $h$ is the depth of the ocean surface mixed layer. Because estimates of mixedlayer depth are not available for the entire region with the required time resolution of $\sim 1$ day, for the heat budget analysis we proceed similarly to Flynn et al. (2017) and use a constant mixed-layer depth of $h=20 \mathrm{~m}$ based on the climatological mean summer mixed layer depths in the region (Holte et al., 2010). The residual $R$ includes terms due to penetrating radiation that passes below the mixed layer, horizontal advection and horizontal eddy dispersion of climatological and anomalous SST gradients by the climatological and anomalous velocity fields, changes in mixedlayer depth with time, and vertical variations in velocity and temperature within the mixed layer (see e.g., Flynn et al., 2017, for details). The penetrating radiation term is typically negligible in this region (Flynn et al., 2017), as is the effect of vertical variations within the mixed layer if the layer is relatively wellmixed. Away from the $\sim 200-\mathrm{km}$ wide upwelling zone near the coast, the horizontal advection and dispersion terms are typically also negligible on time scales of a few days (Swenson and Niiler, 1996; Flynn et al., 2017). Therefore, on time scales of a few days, the most important terms in the residual are likely associated with vertical processes, such as changes in entrainment at the base of the mixed layer. For the heat budget, instead of the CMC SST we use the SST from OAFlux (section 2.2) for consistency with the air-sea flux estimates.

\section{RESULTS}

\subsection{Similarity of the SST Anomaly Pattern in July 2015 to a Known Regional Wind Pattern}

There is a striking similarity between the spatial structure of the regional SST anomaly off central California during midJuly 2015 (Figure 1B) and the typical spatial structure of wind relaxation events off central California [section 1.2 and Fewings et al. (2016), their Figure 6, day 2]. The warm SST anomaly that forms the southern part of the split MHW in Figure 1B is roughly triangular, with the apex near Cape Mendocino and the region of unusually warm SST widening toward the equator and extending hundreds of kilometers offshore and southward. The warm SST anomaly is connected to the coast from Cape Mendocino to Point Conception. From Point Conception southward, however, the warm SST anomaly is separated from the coast; the Southern California Bight and the coastal waters along Baja California do not have strong SST anomalies in mid-July 2015. The region of warming SST and weak wind during typical "southern relaxation" events has the same triangular structure (sections 1.2, 1.3). Motivated by this similarity, we examine whether the wind anomalies exhibit a southern relaxation during the days or weeks preceding the 15 July 2015 split MHW SST pattern in Figure 1B.

\subsection{Unusual Persistence of "Southern Relaxation" Wind Pattern Before the Split MHW}

During the MHW in summer 2015, the regional wind relaxations persisted longer than in a typical summer. In a more typical year, the relaxation events tend to last 2-5 days (Melton et al., 2009; Fewings et al., 2016). An example of a typical summer, 2009, is shown in Figure 3A. In contrast, in summer 2015 the relaxations typically lasted 1-2 weeks (red in Figure 3C). These unusually long relaxations are consistent with the persistent mid-level ridging that led to the large-scale MHW in the GoA (section 1.1): because mid-level ridging on synoptic 

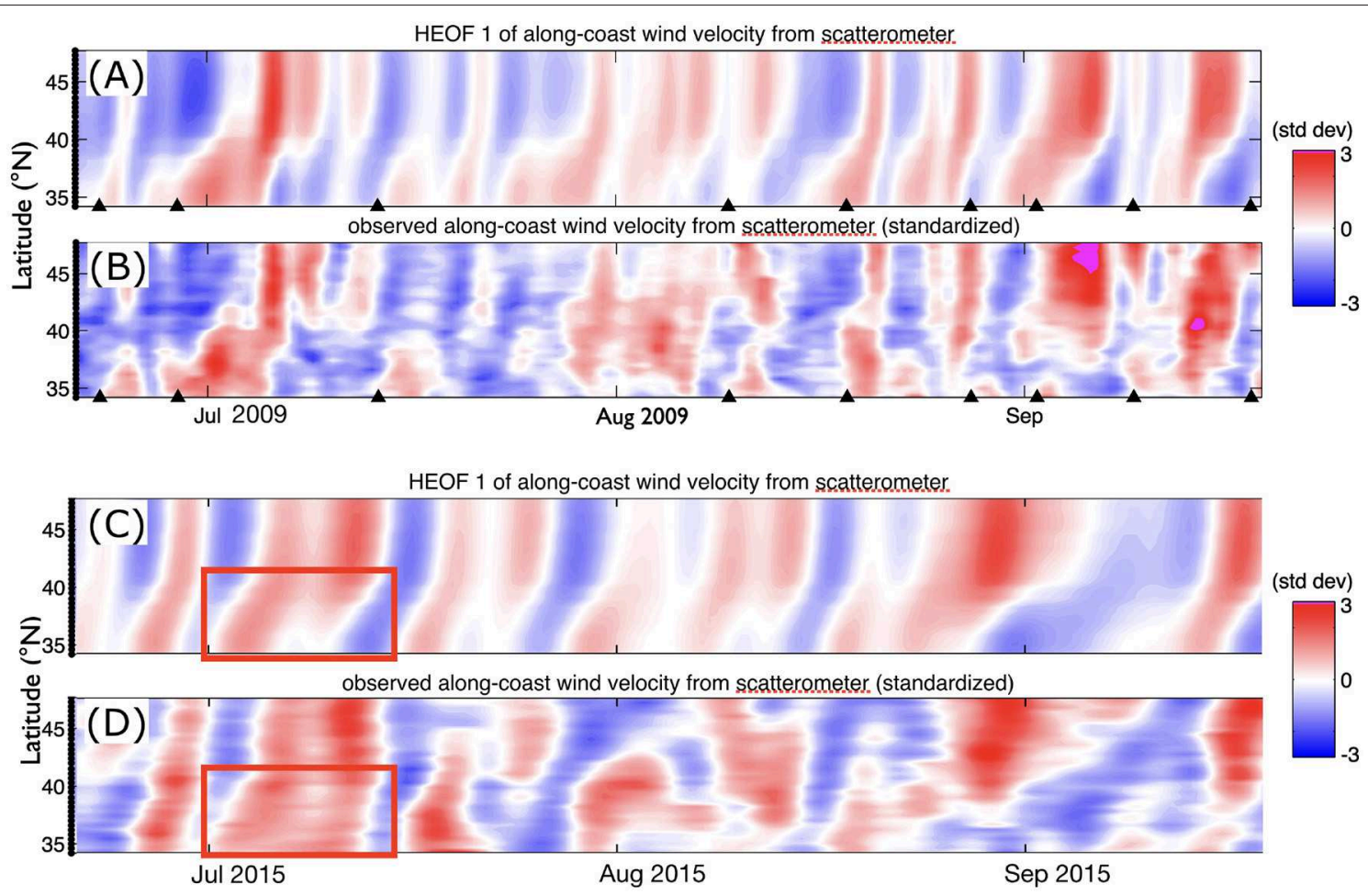

FIGURE 3 | Hovmoller diagrams of along-coast wind velocity and HEOF 1 of wind velocity along the west coast of the United States during summer: (A,B) 2009 from QuikSCAT and (C,D) 2015 from ASCAT. In (B,D) the mean wind velocity was removed and the data scaled by the standard deviation of wind velocity at each site. For (C), the wind velocities from ASCAT in 2015 were projected onto the HEOF 1 spatial pattern calculated in Fewings (2017). Red boxes indicate 1-14 July 2015, the period preceding the appearance of the split MHW. Red indicates the along-coast wind velocity is below the mean value at that location (i.e., a wind relaxation is occurring). Panels (A,B) are reused from Fewings (2017) with permission; black triangles indicate the onset of wind relaxations at Point Conception, California discussed in that study.

time scales causes the southern relaxation state of the wind dipole off the western continental U.S. (section 1.2), it is not surprising that the more persistent mid-level ridging during 2014-2016 (Bond et al., 2015; Hartmann, 2015) was associated with more persistent southern relaxations. A particularly prolonged wind relaxation occurred during 1-14 July 2015 (red boxes in Figures 3C,D). This 2-week period encompassed the transition of the MHW from a single "Blob" in the GoA (Figure 1A) to a split MHW structure with two warm anomalies, one in the GoA and one off California (Figure 1B). Therefore, we focus on the 114 July 2015 period as a case study for the development of a split MHW structure during regional wind relaxation.

The spatial structure of the wind anomalies during the extended "southern relaxation" of 1-14 July 2015 is qualitatively consistent with the more typical synoptic wind relaxations described in section 1.2. The average wind stress anomalies during that 2 -week period did have a dipole structure, with stronger than typical winds in the north part of the study region (blue in Figure 2C) and weakened winds (red in Figure 2C) south and west of Cape Mendocino in a roughly triangular shape with the apex near the Cape. Consistent with the more typical synoptic relaxation events discussed in sections $1.2,1.3$, the region with weakened winds in 1-14 July 2015 is similar in shape to the region of warm SST anomaly that developed off California during the same period (Figure 1B). Note that this 2-week wind forcing anomaly is likely to dominate a monthly average wind forcing anomaly, but may simultaneously not be well-represented by a monthly average. To understand how this wind relaxation was related to the SST anomaly in Figure 1B, below we consider a heat budget for the ocean surface mixed layer.

\subsection{Small Air-Sea Heat Flux Anomalies in the Warm SST Anomaly Region}

To determine whether air-sea heat flux anomalies associated with the wind relaxation of 1-14 July 2015 could explain the warm SST anomaly that developed off California, we examine the ocean surface mixed layer heat budget during that period. First, we consider the trend in SST anomaly during 1-14 July 2015. The SST anomalies relative to climatology increased by $\geq 1{ }^{\circ} \mathrm{C}$ over most of the region in and offshore of the CCS (red in Figure 4A extending from marked area 1 to area 3 ). The anomalous warming was strongest offshore of central and southern California, where the SST anomaly increased by $\sim 3.5^{\circ} \mathrm{C}$ (Figure 4A). The SST anomaly decreased during this period in the open ocean $\sim 1000 \mathrm{~km}$ offshore of California (region 3 in Figure 4A). To determine whether anomalies in atmosphere-ocean heat flux can explain these areas of anomalous warming and cooling, we used the 

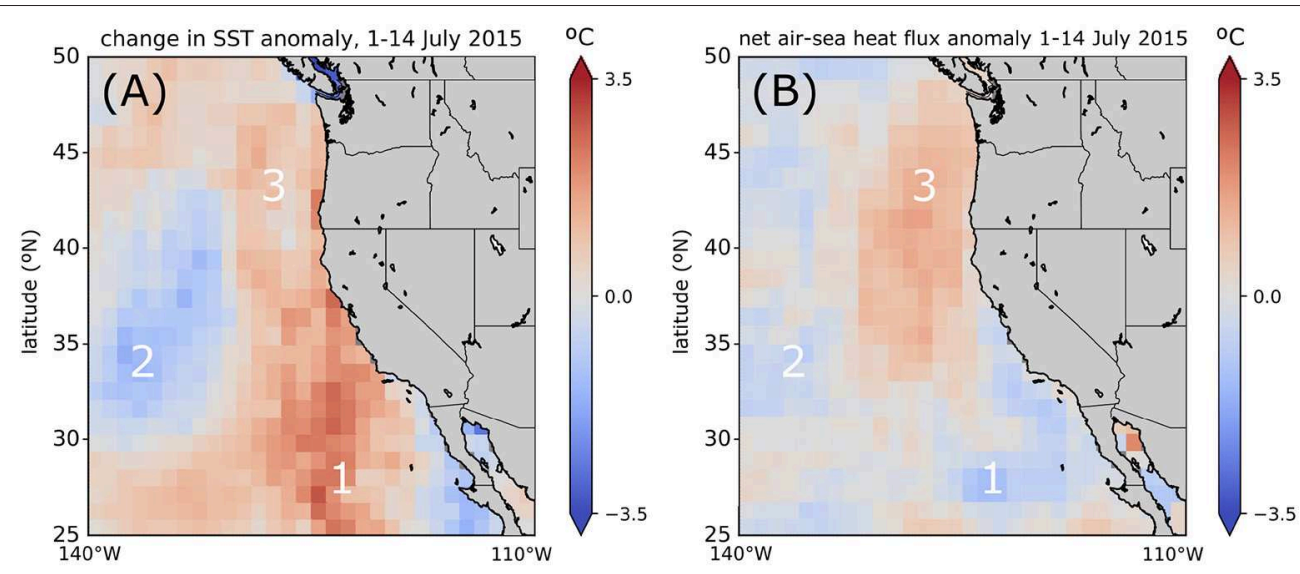

FIGURE 4 | Terms in a time-integrated 1-D heat anomaly budget for the ocean surface mixed layer (section 3.4) during 1-14 July 2015. (A) Change in SST anomaly from 1 July to 14 July at each location, relative to a daily climatology. (B) Accumulated anomaly in the net air-sea heat flux during 1-14 July. Positive indicates anomalous ocean warming (or equivalently, weaker cooling than in the climatology). If the 1-D heat budget closed exactly, the two panels would look the same. For consistency, (A) is based on the SST product distributed with OAFlux, not the CMC SST used elsewhere in this study, but the CMC product gives a very similar result (not shown). To facilitate comparison with (A), the heat flux anomalies in (B) are converted to the change in SST that would be generated for a climatological mixed layer depth of $\sim 20 \mathrm{~m}$, following Flynn et al. (2017) (i.e., each heat flux is scaled by $\rho_{0} c_{p} h$ with $h=20$ m). White numbers mark regions referred to in section 4.3 .

OAFlux and CERES products to estimate terms in the mixed layer heat budget as described in section 3.4. The main features are described below for the regions marked $1-3$ in Figures 4, 5 .

- Region 1: The net air-sea heat flux anomaly was negative south of Point Conception and offshore of Baja California (region 1, Figure 4B). The CERES product indicates this negative air-sea heat flux anomaly was mostly due to reduced net shortwave radiation ("more cloudy" in Figure 5A) that overcame a small increase in net longwave radiation (light red in Figure 5B). These radiative flux anomalies are attributable to unusually cloudy conditions. The clouds typically observed in the region in this season are low marine stratus (Iacobellis and Cayan, 2013). For an increase in this type of cloud, the resulting decrease in downwelling shortwave radiation tends to outweigh the increase in downwelling longwave radiation, leading to a net reduction in radiative ocean warming (Hartmann et al., 1992; Klein and Hartmann, 1993). There was also some contribution from a negative anomaly in latent heat flux, i.e., there was increased evaporation (light blue along southern California and Baja in region 1 of Figure 5C).

The negative air-sea heat flux anomaly in region 1 (blue, Figure 4B) is the wrong sign to explain the warming in SST observed in the same region (red in Figure 4A), so the residual in the $1-\mathrm{D}$ heat budget is large (red in region 1 in Figure 6A).

- Region 2: In part of the offshore region where SST cooled (region 2 in Figure 4A), the net air-sea heat flux anomaly was negative (blue in region 2 in Figure 4B). The negative heat flux anomaly is again attributable to an increase in cloudiness (blue in region 2 in Figure 5A). In this relatively small region, the air-sea heat flux anomaly does explain part of the observed change in SST anomaly, and the residual in the 1-D heat budget is smaller in region 2 than in region 1 (Figure 6A). However, air-sea flux does not explain all the cooling in SST offshore in Figure 4A; there is residual, unexplained cooling in the northern part of the region where SST cooled (blue between 2 and 3 in Figure 6A).

- Region 3: The net air-sea flux anomaly was positive in the region along Washington and Oregon (red in region 3 in Figure $4 \mathbf{B}$ ). The anomalous warming was mainly due to increased shortwave radiation, i.e., reduced cloudiness (red in region 3 in Figure 5A). In this region, the air-sea heat flux anomaly accounts for enough heating to explain the observed change in SST anomaly, and the residual has a smaller magnitude than in region 1 (light blue in region 3 in Figure 6A).

In general, the net air-sea heat flux anomalies during 1-14 July 2015 cannot explain the strong warming in SST to the west and south of California during that period (region 1 in Figure 4A). If the heat budget for the mixed layer were a 1-D (vertical) balance between air-sea heat flux and change in SST, Figures 4A,B would look the same. Instead, those panels look very different except off Washington/Oregon (region 3) and in one part of the region where SST cooled anomalously (region 2). Strikingly, in the region of greatest SST increase (region 1), the anomaly in net air-sea heat flux was near zero or the wrong sign to explain the increase in SST.

The failure of air-sea heat flux anomalies to account for the observed ocean warming off California is consistent with the heat budget in the shorter-lived "southern wind relaxation" events in Flynn et al. (2017). During typical synoptic southern relaxations, (i) the net air-sea heat flux anomalies are small in 

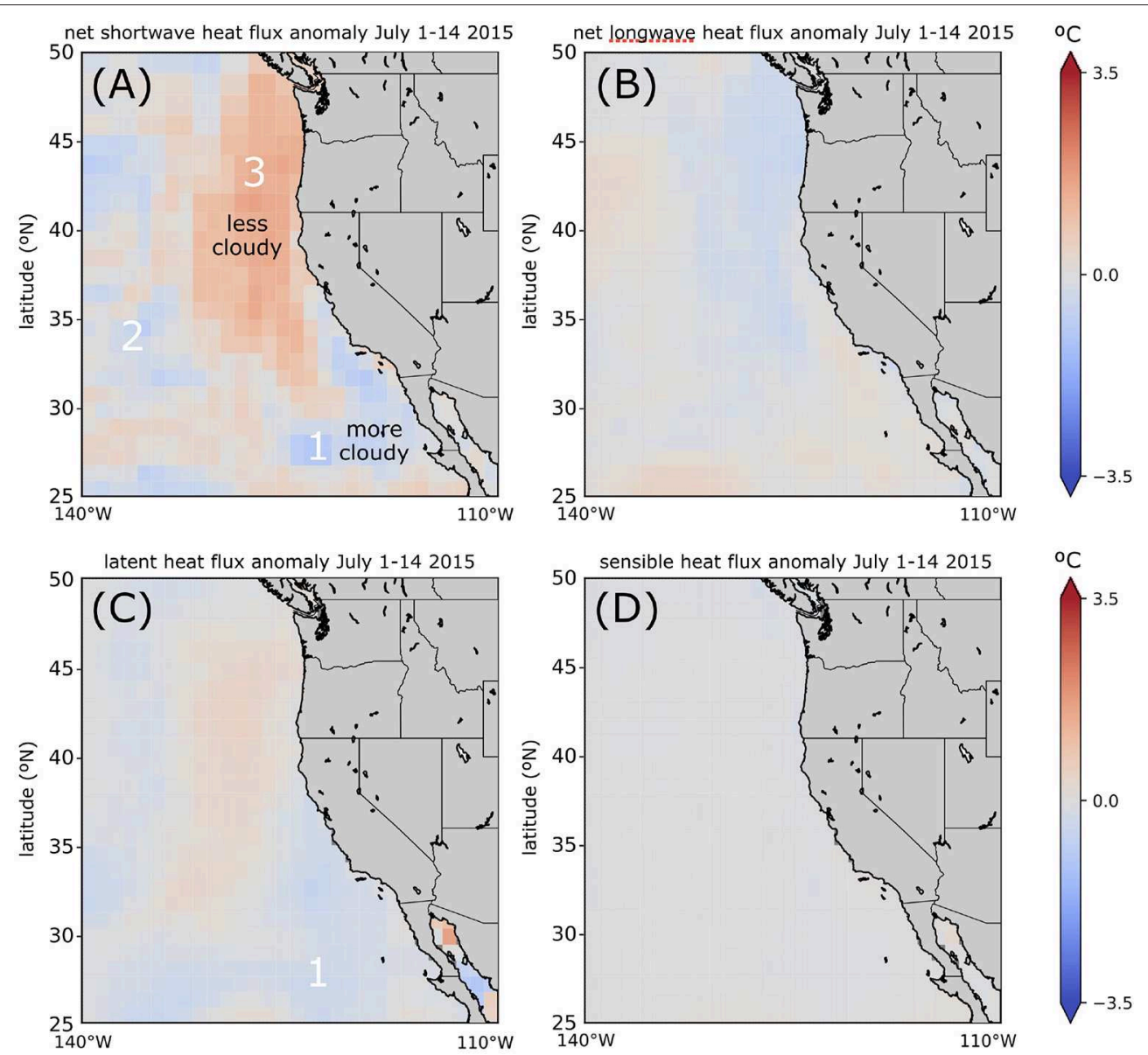

FIGURE 5 | Components of the net air-sea heat flux anomaly in the time-integrated 1-D budget during 1-14 July 2015 (Figure 4B). Positive indicates anomalous ocean warming (or equivalently, weaker cooling than in the climatology). The panels show accumulated anomalies in (A) net shortwave radiation, (B) net longwave radiation, (C) latent heat flux, and (D) sensible (conductive) heat flux. To facilitate comparison with Figure $\mathbf{4}$, the heat flux anomalies have again been converted to the change in SST that would be generated for a climatological mixed layer depth of $\sim 20 \mathrm{~m}$, following Flynn et al. (2017) (i.e., each heat flux is scaled by $\rho_{0} c_{p} h$ with $h=20 \mathrm{~m})$. The color scale is the same for all panels. White numbers mark regions referred to in section 4.3.

the region of weak winds, and (ii) the region of weak winds is where the greatest warming occurs (section 1.3). During the more persistent relaxation in July 2015, the same general pattern holds: (i) the air-sea heat flux anomalies during 1-14 July 2015 are small or negative (region 1, Figure 4B) in the region of weak winds (red in Figure 6B), which (ii) coincides with the region of strongest warming (region 1, Figure 4A). The partial success of air-sea heat flux anomaly in accounting for SST changes in the northern region of intensified winds during 114 July 2015 (region 2) is also consistent with the heat budget in the more typical synoptic events described in Flynn et al. (2017). The magnitude of SST warming off California during the July 2015 event, $\sim 3^{\circ} \mathrm{C}$, is much larger than for typical events, $O\left(0.25-0.5^{\circ} \mathrm{C}\right)$ (Flynn et al., 2017). Nevertheless, because the air-sea heat flux anomalies are too small to explain much of the SST anomaly pattern (as discussed above), the most likely explanation for the SST changes in early July 2015 is changes in wind-driven mixing and entrainment, as in the more typical synoptic events (the anomaly in wind stress curl is negligible offshore; not shown). Supporting this interpretation that changes in wind-driven mixing or entrainment are important in driving the SST anomalies, the spatial pattern of the residual heating and cooling "missing" from the heat budget (Figure 6A) is strikingly similar to the spatial pattern of the change in mean wind stress magnitude during the same period (Figure 6B).

\subsection{Forming SST and Wind Stress Anomalies With the Same Shape: Persistence Is Key}

The SST tendency during 1-14 July 2015 (Figure 4A; also see Appendix in Supplementary Material for daily SST anomaly plots) off California has a spatial pattern similar to the wind stress anomalies during the same period (Figures 2B, 6B), with the SST and wind stress anomalies having opposite signs. The unusual persistence of this southern wind relaxation was key to the development of an SST anomaly, rather than only an SST trend, in the shape of the wind anomaly. During more typical 

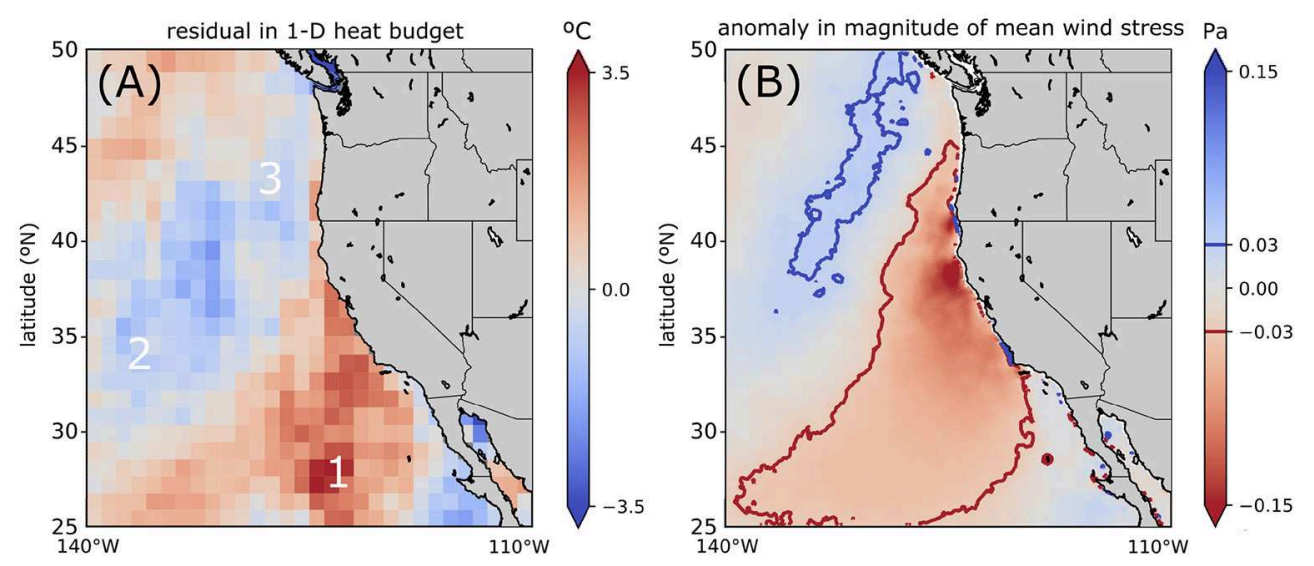

FIGURE 6 | (A) Residual in the 1-D budget for the ocean surface mixed layer heat anomaly during 1-14 July 2015, equal to Figure 4A minus Figure 4B. Red indicates unexplained ocean warming. (B) Anomaly in the magnitude of the mean wind stress during 1-14 July 2015, equal to the magnitude of the arrows in Figure 2B minus the magnitude of the arrows in Figure 2A. Note that in (B), red indicates weaker mean wind stress, and blue indicates stronger mean wind stress, in 2015 as compared to 2000-2017. This reversed color convention for the wind stress anomaly is to facilitate comparison of the two panels. The \pm 0.03 Pa contours are shown as a threshold for a non-negligible wind stress anomaly, following previous studies (e.g., Fewings et al., 2008). White numbers mark regions referred to in section 4.3 .

shorter wind relaxation events off California, the warming in SST is not strong enough to dominate over preexisting SST anomalies (section 1.3). During 1-14 July 2015, however, the warming trend in SST in the region of relaxed winds lasted so long that it overcame preexisting SST anomalies, resulting in an SST anomaly with the triangular shape of the California-scale region of high winds (Edwards et al., 2002) that is "turned off" during southern wind relaxations (section 1.2).

\section{DISCUSSION}

\subsection{Development of a Split MHW}

When superimposed on the preexisting northeast Pacific MHW, the changes in SST during 1-14 July 2015 (Figure 4A) can explain the split MHW structure previously described as part of Phase III of the MHW (Peterson et al., 2016), as well as the "cool corridor" described in Gentemann et al. (2016). We propose the following scenario for the development of a split MHW. First, persistent mid-level ridging leads to the formation of a MHW in the GoA (e.g., Bond et al., 2015; Hartmann, 2015) (Figure 7, top left). Second, during summer the persistent ridging prolongs a typical synoptic wind relaxation off California, causing the "southern relaxation" wind pattern to last for weeks instead of the usual few days (e.g., Figures 3C,D, 7, top right). Third, this prolonged weak wind anomaly off California causes a warming trend in SST; conversely, the strong wind anomaly off the northern half of the CCS causes a cooling trend in SST (Figure 4A, regions 1 and 2). This dipole in SST trends lasts long enough to create a dipole SST anomaly pattern with the same spatial pattern but opposite sign from the wind anomalies: colder SST off Washington/Oregon and warmer SST off California (Figure 7, lower right). When superimposed on the preexisting MHW in the GoA, this CCS SST dipole creates a split MHW SST pattern, with warm SSTs in the GoA, a "cool corridor" (Gentemann et al., 2016) extending offshore from the northern CCS, and warm SSTs off California (Figures 1B, 7, bottom left).

Key aspects of the formation of the split MHW are (a) atmospheric ridging leads to both a MHW in the GoA and unusual persistence of the southern wind relaxation pattern off the western continental U.S., (b) the southern wind relaxation persists long enough for the resulting trends in SST to overcome any preexisting SST anomalies offshore of the CCS, (c) the resulting dipole SST anomaly is dominated by anomalies in winddriven mixing, not air-sea flux anomalies, so (d) the spatial structure of the new SST anomaly is similar to the spatial structure of the wind anomaly, and (e) the spatial structure of the wind anomaly is set by the shape of the coastline and resulting expansion fan (Edwards et al., 2002). The end result is that persistent atmospheric ridging creates not only a warm SST anomaly in the GoA but also a warm SST anomaly shaped like a triangle extending southward from Cape Mendocino. Together, these two warm anomalies form the split MHW. The split MHW structure is further enhanced by the cold SST anomaly in between the two warm anomalies, which is associated with the wind intensification offshore of Washington/Oregon that accompanies southern wind relaxation and forms the other half of the wind dipole (Figures 2C, 6B, blue). Overall, we propose that the split MHW of July 2015 occurred when the wind dipole mode endemic to the CCS (Fewings, 2017), during a particularly persistent southern relaxation, imprinted a dipole SST anomaly on top of the pre-existing northeast Pacific warm SST anomaly.

\subsection{Similarities and Differences Between Typical and Prolonged Wind Relaxations}

To first order, the dynamics of the "extreme" or prolonged southern relaxation event during 1-14 July 2015 are the same as more typical synoptic wind quasi-dipole events described 


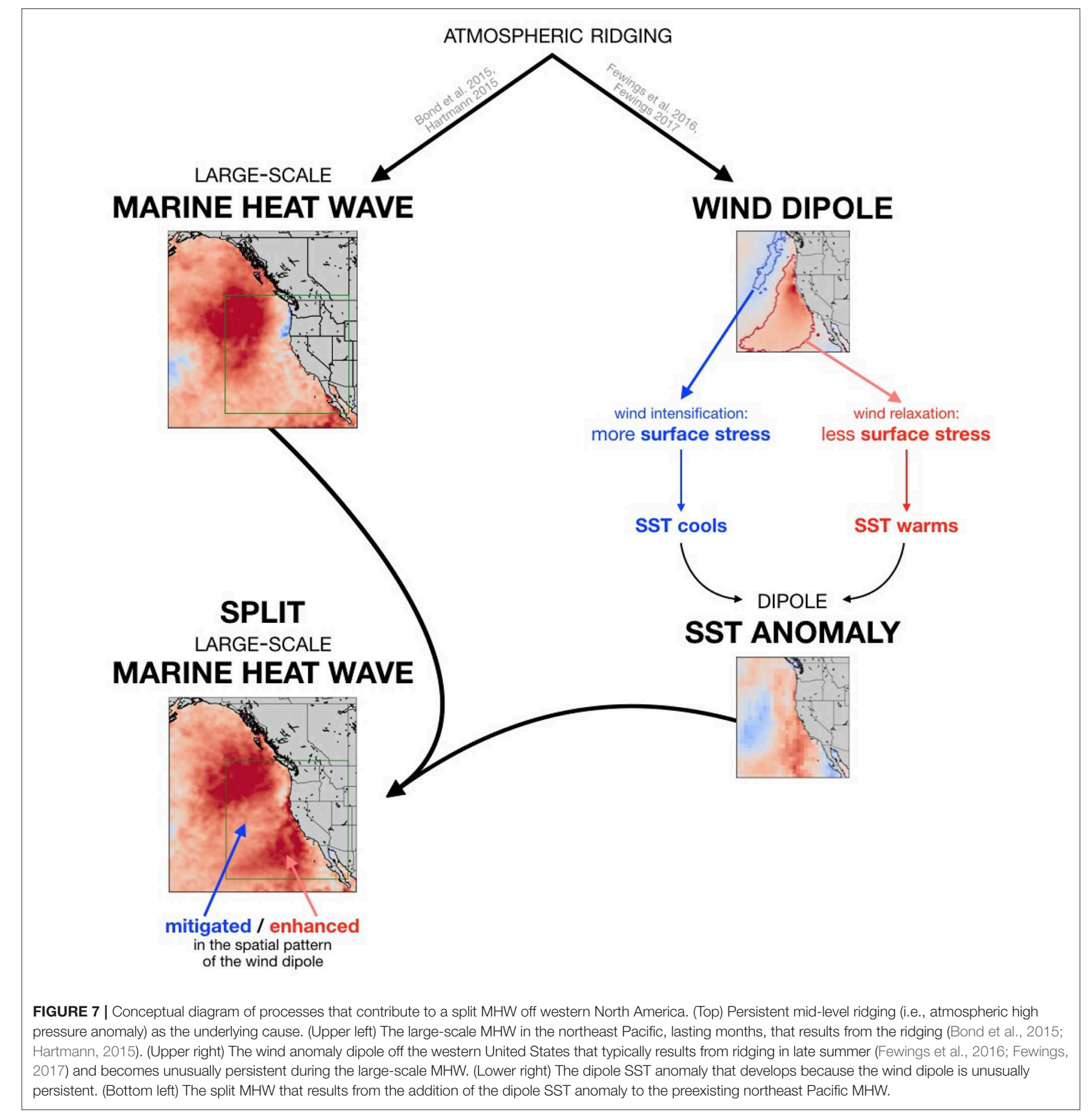

in Fewings et al. (2016) and Flynn et al. (2017). The net airsea heat flux anomaly is too small to explain the SST anomaly (section 4.3, region 1), so we infer the SST signal is due to reduced wind-driven mixing and mixed-layer shoaling, as in more typical shorter events Flynn et al. (2017).

There are some details that differ between the prolonged relaxation event of July 2015 and the typical synoptic relaxation events. (a) The node of the dipole wind anomaly along the coast was farther poleward during 1-14 July 2015 (Figure 2B) than during typical events, in which the node is near Cape Mendocino (Fewings et al., 2016). (b) It is possible that during very prolonged wind relaxations, changes in horizontal advection of temperature gradients could become important even in the region offshore of the upwelling zone, as the scaling analysis for that term assumes synoptic time scales of days (Flynn et al., 2017). 


\subsection{Implications for the Spatial Structure of Future MHW in the CCS}

The association of persistent ridging, persistent southern wind relaxation, and development of a split MHW with a particular shape determined by a coastline bend lends insight into which areas along the western continental U.S. are likely to have enhanced or mitigated SST anomalies during future MHWs. We expect that future large-scale MHWs similar to the 2014-2016 event will also split into two parts along the western continental U.S. during the summer. This region includes the California Current eastern boundary upwelling system, which supports substantial export production and fisheries (e.g., Falkowski et al., 1998). Species shifts and fisheries and ecosystem disruptions may still occur across the entire system due to the effects of the $\mathrm{MHW}$ in fall and winter before the MHW is mitigated along the coast at the beginning of upwelling season and then splits in two during the upwelling season, as observed during 2014-2016 (Gentemann et al., 2016). However, our expectation is that warm SST anomalies and associated ecosystem disruptions during the summer will be stronger in the southern than the northern half of the upwelling system. Based on the particular relation of SST anomalies to wind stress anomalies offshore of the CCS region, the spatial structure of future MHWs off western North America in summer may be forseeable, even if the timing of the MHWs is not.

\subsection{A Corollary for Future Climate?}

It has been suggested that the prevailing summertime equatorward wind forcing along eastern ocean boundaries in midlatitudes, i.e., over the CCS and other eastern boundary upwelling systems (EBUS), will strengthen in a warming global climate due to enhanced temperature contrast between ocean and land (Bakun and Nelson, 1991). In contrast, simulations with the Community Earth System Model suggest that summer mean wind forcing patterns over EBUS will not strengthen, but will shift poleward (Rykaczewski et al., 2015). In the case of the CCS, this would result in stronger upwelling-favorable wind forcing on average over the poleward half of the system, off Oregon, and weaker wind forcing on average off California. Because the wind fluctuations over the CCS are comparable to or stronger than the mean (Halliwell and Allen, 1987), a change in the mean wind forcing requires a change in the statistics of the fluctuations. Therefore, the suggested changes in the mean wind forcing in a warmer climate imply the system would spend more time in the southern wind relaxation state described in Bond et al. (1996) and Fewings et al. (2016). If the MHW of 2014-16, and in particular the 1-14 July 2015 pattern discussed in this study, can be viewed as an example of the future climate "normal" for EBUS, then this study supports the suggestion in Rykaczewski et al. (2015) of strengthened wind forcing over the poleward half of the California Current system and weakened wind forcing in the equatorward half. Based on the relation of warm SSTs to the region of relaxed winds described here, if the relation of wind relaxations to increased cloudiness off California also persists in a warmer climate, then the future climate "normal" for the CCS will have warmer SSTs compared to today from Cape Mendocino southward, and cooler SSTs from Cape Mendocino northward.

\subsection{Summary}

This analysis was driven by the striking similarity between recent MHWs off the western continental U.S. and a previously described regional wind relaxation dipole. This case study suggests that a characteristic regional wind dipole pattern off Washington, Oregon, and California in summer (Fewings, 2017), which has a spatial structure determined by the coastline shape (Edwards et al., 2002) and is triggered by atmospheric ridging (Nuss, 2007), played a crucial role in determining the regional spatial structure of the MHW of 2015. We suggest that during the extended midlatitude MHWs off western North America during 2014-2016, and due to the accompanying persistent ridging, the wind dipole mode persisted unusually long in the "southern relaxation" state described by Fewings et al. (2016) and Fewings (2017). This reduced and increased SST in the poleward and equatorward parts of the domain, respectively, thus "splitting" the MHW. If the air-sea flux anomalies during wind relaxations over other eastern boundary upwelling regions are small as in the CCS, the summer wind patterns set by the coastlines of the ChilePeru, Benguela, and Canary Current Systems may also provide projections for the spatial structure of MHW in those systems.

\section{DATA AVAILABILITY}

All data sets analyzed in this work are publicly available through the repositories indicated in Data.

\section{AUTHOR CONTRIBUTIONS}

MF carried out the calculations for Figure 3 and guided the remaining calculations, made Figures 3, 7 and assembled the other figures, and contributed the bulk of the text. KB wrote the python code to carry out the remaining calculations, produced the panels for all figures except Figures 3, 7, and assisted in the writing of the manuscript.

\section{FUNDING}

This work was funded by the NASA RapidSCAT mission through subcontract 1544398 from the Jet Propulsion Laboratory (JPL) and by the NASA Ocean Vector Winds Science Team through grant 80 NSSC18K1611 and JPL subcontracts 1531731 and 1624044 .

\section{ACKNOWLEDGMENTS}

We thank Carlos Moffat (University of Delaware), Samantha Siedlecki (University of Connecticut), and Jonathan Nash (Oregon State University) for helpful discussions and Chelle Gentemann (Earth and Space Research) for advice on the CMC satellite SST product.

\section{SUPPLEMENTARY MATERIAL}

The Supplementary Material for this article can be found online at: https://www.frontiersin.org/articles/10.3389/fmars. 2019.00564/full\#supplementary-material 


\section{REFERENCES}

Auth, T. D., Daly, E. A., Brodeur, R. D., and Fisher, J. L. (2017). Phenological and distributional shifts in ichthyoplankton associated with recent warming in the northeast pacific ocean. Glob. Change Biol. 24, 259-272. doi: 10.1111/gcb.13872

Bakun, A., and Nelson, C. S. (1991). The seasonal cycle of wind-stress curl in subtropical eastern boundary current regions. J. Phys. Oceanogr. 21, 1815-1834. doi: 10.1175/1520-0485(1991)021<1815:TSCOWS >2.0.CO;2

Bane, J. M., Levine, M. D., Samelson, R. M., Haines, S., Meaux, M., Perlin, N., et al. (2005). Atmospheric forcing of the Oregon coastal ocean during the 2001 upwelling season. J. Geophys. Res. 110:C10S02. doi: 10.1029/2004JC002653

Bane, J. M., Spitz, Y. H., Letelier, R. M., and Peterson, W. T. (2007). Jet stream intraseasonal oscillations drive dominant ecosystem variations in Oregon's summertime coastal upwelling system. Proc. Natl. Acad. Sci. U.S.A. 104, 1326213267. doi: 10.1073/pnas.0700926104

Barnard, P. L., Hoover, D., Hubbard, D. M., Snyder, A., Ludka, B. C., Allan, J., et al. (2017). Extreme oceanographic forcing and coastal response due to the 2015-2016 El Niño. Nat. Commun. 8:14365. doi: 10.1038/ncomms 14365

Benjamini, Y., and Hochberg, Y. (1995). Controlling the false discovery rate: a practical and powerful approach to multiple testing. J. R. Stat. Soc. B Methodol. 57, 289-300. doi: 10.1111/j.2517-6161.1995.tb02031.x

Bond, N. A., Cronin, M. F., Freeland, H., and Mantua, N. (2015). Causes and impacts of the 2014 warm anomaly in the NE Pacific. Geophys. Res. Lett. 42, 3414-3420. doi: 10.1002/2015GL0633062015GL063306

Bond, N. A., Mass, C. F., and Overland, J. E. (1996). Coastally trapped wind reversals along the United States west coast during the warm season. Part I: climatology and temporal evolution. Monthly Weather Rev. 124, 430-445.

Brasnett, B. (2008). The impact of satellite retrievals in a global sea-surfacetemperature analysis. Q. J. R. Meteorol. Soc. 134, 1745-1760. doi: 10.1002/ qj.319

Canada Meteorological Center (2012). GHRSST Level 4 CMC0.2deg Global Foundation Sea Surface Temperature Analysis (GDS version 2). Ver. 2.0. PO.DAAC, CA. Available online at: https://podaac.jpl.nasa.gov/dataset/CMC0. 2deg-CMC-L4-GLOB-v2.0 (accessed April 9, 2019).

Cavole, L. M., Demko, A. M., Diner, R. E., Giddings, A., Koester, I., Pagniello, C. M., et al. (2016). Biological impacts of the 2013-2015 warm-water anomaly in the Northeast Pacific: winners, losers, and the future. Oceanography 29, 273-285. doi: 10.5670/oceanog.2016.32

Chao, Y., Farrara, J. D., Bjorkstedt, E., Chai, F., Chavez, F., Rudnick, D. L., et al. (2017). The origins of the anomalous warming in the California coastal ocean and San Francisco Bay during 2014-2016. J. Geophys. Res. Oceans 122, 7537-7557. doi: 10.1002/2017JC013120

Clayson, C. A., Brown, J., and NOAA CDR Program (2016). NOAA Climate Data Record Ocean Surface Bundle (OSB) Climate Data Record (CDR) of Ocean Heat Fluxes, Version 2. NOAA National Center for Environmental Information. doi: 10.7289/V59K4885 (accessed July 17, 2019).

Daly, E. A., Brodeur, R. D., and Auth, T. D. (2017). Anomalous ocean conditions in 2015: impacts on spring Chinook salmon and their prey field. Mar. Ecol. Progr. Series 566, 169-182. doi: 10.3354/meps12021

Di Lorenzo, E., and Mantua, N. (2016). Multi-year persistence of the 2014/15 North Pacific marine heatwave. Nat. Clim. Change 6, 1042-1047. doi: $10.1038 /$ nclimate3082

Du, X., and Peterson, W. (2018). Phytoplankton community structure in 20112013 compared to the extratropical warming event of 2014-2015. Geophys. Res. Lett. 45, 1534-1540. doi: 10.1002/2017GL076199

Edson, J. B., Jampana, V., Weller, R. A., Bigorre, S. P., Plueddemann, A. J., Fairall, C. W., et al. (2013). On the exchange of momentum over the open ocean. J. Phys. Oceanogr. 43, 1589-1610. doi: 10.1175/JPO-D-12-0173.1

Edwards, K. A., Rogers, D. P., and Dorman, C. E. (2002). Adjustment of the marine atmospheric boundary layer to the large-scale bend in the California coast. J. Geophys. Res. 107, 3213. doi: 10.1029/2001jc000807

Falkowski, P. G., Barber, R. T., and Smetacek, V. (1998). Biogeochemical controls and feedbacks on ocean primary production. Science 281, 200-206. doi: 10.1126/science.281.5374.200

Fewings, M. R. (2017). Large-scale structure in wind forcing over the California Current System in summer. Monthly Weather Rev. 145, 4227-4247. doi: 10.1175/MWR-D-17-0106.1
Fewings, M. R., Lentz, S. J., and Fredericks, J. (2008). Observations of crossshelf flow driven by cross-shelf winds over the inner continental shelf. J. Phys. Oceanogr. 38, 2358-2378. doi: 10.1175/2008JPO3990.1

Fewings, M. R., Washburn, L., Dorman, C. E., Gotschalk, C., and Lombardo, K. (2016). Synoptic forcing of wind relaxations at Pt. Conception, California. J. Geophys. Res. 121, 5711-5730. doi: 10.1002/2016JC011699

Fisher, R. A. (1992). Statistical Methods for Research Workers. New York, NY: Springer New York, 66-70.

Flynn, K. R., Fewings, M. R., Gotschalk, C., and Lombardo, K. (2017). Large-scale anomalies in sea-surface temperature and air-sea fluxes during wind relaxation events off the United States West Coast in summer. J. Geophys. Res. Oceans 122, 2574-2594. doi: 10.1002/2016JC012613

Fore, A. G., Stiles, B. W., Chau, A. H., Williams, B. A., Dunbar, R. S., and Rodríguez, E. (2014). Point-wise wind retrieval and ambiguity removal improvements for the QuikSCAT climatological data set. IEEE Trans. Geosci. Rem. Sens. 52, 51-59. doi: 10.1109/TGRS.2012.2235843

Frischknecht, M., Münnich, M., and Gruber, N. (2017). Local atmospheric forcing driving an unexpected California Current System response during the 20152016 El Niño. Geophys. Res. Lett. 44, 304-311. doi: 10.1002/2016GL071316

Gentemann, C. L., Fewings, M. R., and García-Reyes, M. (2016). Satellite sea surface temperatures along the West Coast of the United States during the 2014-2016 northeast Pacific marine heat wave. Geophys. Res. Lett. 44, 312-319. doi: 10.1002/2016GL071039

Gomez-Ocampo, E., Gaxiola-Castro, G., Durazo, R., and Beier, E. (2018). Effects of the 2013-2016 warm anomalies on the California Current phytoplankton. Deep Sea Res. II Top. Stud. Oceanogr. 151, 64-76. doi: 10.1016/j.dsr2.2017.01.005

Halliwell, G. R., and Allen, J. S. (1987). The large-scale coastal wind field along the west coast of North America, 1981-1982. J. Geophys. Res. 92, 1861-1884.

Hannachi, A., Jolliffe, I. T., and Stephenson, D. B. (2007). Empirical orthogonal functions and related techniques in atmospheric science: a review. Int. J. Climatol. 27, 1119-1152. doi: 10.1002/joc.1499

Hartmann, D. L. (2015). Pacific sea surface temperature and the winter of 2014. Geophys. Res. Lett. 42, 1894-1902. doi: 10.1002/2015GL063083

Hartmann, D. L., Ockert-Bell, M. E., and Michelsen, M. L. (1992). The effect of cloud type on Earth's energy balance: global analysis. J. Clim. 5, 1281-1304. doi: 10.1175/1520-0442(1992)005<1281:TEOCTO >2.0.CO;2

Holbrook, N. J., Scannell, H. A., Sen Gupta, A., Benthuysen, J. A., Feng, M., Oliver, E. C. J., et al. (2019). A global assessment of marine heatwaves and their drivers. Nat. Commun. 10:2624. doi: 10.1038/s41467-019-10206-Z

Holte, J., Gilson, J., Talley, L., and Roemmich, D. (2010). Argo Mixed Layers. San Diego, CA: Scripps Institution of Oceanography/University of California. Available online at: http://mixedlayer.ucsd.edu (accessed March 1, 2016).

Iacobellis, S. F., and Cayan, D. R. (2013). The variability of California summertime marine stratus: impacts on surface air temperatures. J. Geophys. Res. Atmos. 118, 9105-9122. doi: 10.1002/jgrd.50652

Jacox, M. G., Hazen, E. L., Zaba, K. D., Rudnick, D. L., Edwards, C. A., Moore, A. M., et al. (2016). Impacts of the 2015-2016 El Niño on the California Current system: early assessment and comparison to past events. Geophys. Res. Lett. 43, 7072-7080. doi: 10.1002/2016GL069716

Jacox, M. G., Tommasi, D., Alexander, M. A., Hervieux, G., and Stock, C. A. (2019). Predicting the evolution of the 2014-2016 California Current System marine heatwave from an ensemble of coupled global climate forecasts. Front. Mari. Sci. 6:497. doi: 10.3389/fmars.2019.00497

Juliano, T. W., Lebo, Z. J., Thompson, G., and Rahn, D. A. (2019). A new perspective on coastally trapped disturbances using data from the satellite era. Bull. Am. Meteorol. Soc. 100, 631-651. doi: 10.1175/BAMS-D-180002.1

Kahru, M., Jacox, M. G., and Ohman, M. D. (2018). CCE1: decrease in the frequency of oceanic fronts and surface chlorophyll concentration in the California Current System during the 2014-2016 northeast Pacific warm anomalies. Deep Sea Res. I Oceanogr. Res. Papers 140, 4-13. doi: 10.1016/j.dsr.2018.04.007

Kintisch, E. (2015). 'The Blob' invades Pacific, flummoxing climate experts. Science 348, 17-18. doi: 10.1126/science.348.6230.17

Klein, S. A., and Hartmann, D. L. (1993). The seasonal cycle of low stratiform clouds. J. Clim. 6, 1587-1606. doi: 10.1175/15200442(1993)006<1587:TSCOLS $>2.0$. CO;2 
KNMI (2010). MetOp-A ASCAT Level 2 Ocean Surface Wind Vectors Optimized for Coastal Ocean. PODAAC-ASOP2-12C01. Ver. Operational/Near-RealTime. PO.DAAC, CA. Available online at: https://podaac.jpl.nasa.gov/dataset/ ASCATA-L2-Coastal (accessed April 3, 2019).

Liang, Y.-C., Yu, J.-Y., Saltzman, E. S., and Wang, F. (2017). Linking the tropical northern hemisphere pattern to the Pacific warm blob and Atlantic cold blob. J. Clim. 30, 9041-9057. doi: 10.1175/JCLI-D-17-0149.1

Lima, F. P., and Wethey, D. S. (2012). Three decades of high-resolution coastal sea surface temperatures reveal more than warming. Nat. Commun. 3:704. doi: $10.1038 /$ ncomms 1713

Mass, C. F., and Bond, N. A. (1996). Coastally trapped wind reversals along the United States west coast during the warm season. Part II: synoptic evolution. Monthly Weather Rev. 124, 446-461.

McCabe, R. M., Hickey, B. M., Kudela, R. M., Lefebvre, K. A., Adams, N. G., Bill, B. D., et al. (2016). An unprecedented coastwide toxic algal bloom linked to anomalous ocean conditions. Geophys. Res. Lett. 43, 10366-10376. doi: 10.1002/2016GL070023

Melton, C., Washburn, L., and Gotschalk, C. (2009). Wind relaxations and poleward flow events in a coastal upwelling system on the central California coast. J. Geophys. Res. 114:C11016. doi: 10.1029/2009JC005397

Myers, T. A., Mechoso, C. R., Cesana, G. V., DeFlorio, M. J., and Waliser, D. E. (2018). Cloud feedback key to marine heatwave off Baja California. Geophys. Res. Lett. 45, 4345-4352. doi: 10.1029/2018GL078242

Neiburger, M., Johnson, D. S., and Chien, C.-W. (1961). The Inversion over the Eastern North Pacific Ocean, Vol. 1 of Studies of the Structure of the Atmosphere Over the Eastern Pacific Ocean in Summer. Berkeley, CA; Los Angeles, CA: University of California Press.

Nuss, W. A. (2007). Synoptic-scale structure and the character of coastally trapped wind reversals. Monthly Weather Rev. 135, 60-81. doi: 10.1175/MWR 3267.1

Nuss, W. A., Bane, J. M., Thompson, W. T., Holt, T., Dorman, C. E., Ralph, F. M., et al. (2000). Coastally trapped wind reversals: progress toward understanding. Bull. Am. Meteorol. Soc. 81, 719-743. doi: 10.1175/15200477(2000)081<0719:CTWRPT>2.3.CO;2

Oliver, E. C. J., Donat, M. G., Burrows, M. T., Moore, P. J., Smale, D. A., Alexander, L. V., et al. (2018). Longer and more frequent marine heatwaves over the past century. Nat. Commun. 9:1324. doi: 10.1038/s41467-018-0 3732-9

Paek, H., Yu, J.-Y., and Qian, C. (2017). Why were the 2015/2016 and 1997/1998 extreme El Niños different? Geophys. Res. Lett. 44, 1848-1856. doi: 10.1002/2016GL071515

Perlin, N., Samelson, R. M., and Chelton, D. B. (2004). Scatterometer and model wind and wind stress in the Oregon-northern California coastal zone. Monthly Weather Rev. 132, 2110-2129. doi: 10.1175/15200493(2004) $132<2110$ :SAMWAW $>2.0$. CO;2

Peterson, W., Bond, N., and Robert, M. (2016). The Blob is gone but has morphed into a strongly positive PDO/SST pattern. PICES Press $24,46-50$.

Peterson, W. T., Fisher, J. L., Strub, P. T., Du, X., Risien, C., Peterson, J., et al. (2017). The pelagic ecosystem in the Northern California Current off Oregon during the 2014-2016 warm anomalies within the context of the past 20 years. J. Geophys. Res. Oceans 122, 7267-7290. doi: 10.1002/2017JC 012952

RapidScat Project (2016). Rapidscat Level $2 B$ Climate Ocean Wind Vectors in 12.5km Footprints. Ver. 1.0. PO.DAAC, CA. Available online at: http://dx.doi. org/10.5067/RSX12-L2C11 (accessed November 12, 2017).

Robinson, C. J. (2016). Evolution of the 2014-2015 sea surface temperature warming in the central west coast of Baja California, Mexico, recorded by remote sensing. Geophys. Res. Lett. 43, 7066-7071. doi: 10.1002/2016GL 069356

Rogerson, A. (1999). Transcritical flows in the coastal marine atmospheric boundary layer. J. Atmos. Sci. 56, 2761-2779.
Rykaczewski, R. R., Dunne, J. P., Sydeman, W. J., García-Reyes, M., Black, B. A., and Bograd, S. J. (2015). Poleward displacement of coastal upwelling-favorable winds in the ocean's eastern boundary currents through the 21 st century. Geophys. Res. Lett. 42, 6424-6431. doi: 10.1002/2015GL064694

Scannell, H. A., Pershing, A. J., Alexander, M. A., Thomas, A. C., and Mills, K. E. (2016). Frequency of marine heatwaves in the North Atlantic and North Pacific since 1950. Geophys. Res. Lett. 43, 2069-2076. doi: 10.1002/2015GL067308

SeaPAC (2016). QuikSCAT Level $2 B$ Ocean Wind Vectors in 12.5- $\mathrm{km}$ Slice Composites Version 3.1. PO.DAAC, CA.

Small, R., deSoeke, S., Xie, S., O'Neill, L., Seo, H., Song, Q., et al. (2008). Airsea interaction over ocean fronts and eddies. Dyn. Atmos. Oceans 45, 274-319. doi: 10.1016/j.dynatmoce.2008.01.001

Swenson, M. S., and Niiler, P. P. (1996). Statistical analysis of the surface circulation of the California Current. J. Geophys. Res. Oceans 101, 22631-22645.

Taylor, S. V., Cayan, D. R., Graham, N. E., and Georgakakos, K. P. (2008). Northerly surface winds over the eastern North Pacific Ocean in spring and summer. J. Geophys. Res. Atmos. 113:D02110. doi: 10.1029/2006JD008053

Tseng, Y.-H., Ding, R., and Meng Huang, X. (2017). The warm Blob in the northeast Pacific-the bridge leading to the 2015/16 El Niño. Environ. Res. Lett. 12:054019. doi: 10.1088/1748-9326/aa67c3

Verhoef, A., Portabella, M., and Stoffelen, A. (2012). High-resolution ASCAT scatterometer winds near the coast. IEEE Trans. Geosci. Rem. Sens. 50, 2481 2487. doi: 10.1109/TGRS.2011.2175001

Verhoef, A., and Stoffelen, A. (2013). Validation of ASCAT Coastal Winds. Technical Report SAF/OSI/CDOP/KNMI/TEC/RP/176, EUMETSAT.

Wallcraft, A. J., Kara, A. B., Barron, C. N., Metzger, E. J., Pauley, R. L., and Bourassa, M. A. (2009). Comparisons of monthly mean $10 \mathrm{~m}$ wind speeds from satellites and NWP products over the global ocean. J. Geophys. Res. Atmos. 114:D16109. doi: 10.1029/2008JD011696D16109

Wang, Y., Liu, H., Lin, P., and Yin, J. (2019). Record-low coastal sea levels in the Northeast Pacific during the winter of 2013-2014. Sci. Rep. 9:3774. doi: 10.1038/s41598-019-40397-w

Whitney, F. A. (2015). Anomalous winter winds decrease 2014 transition zone productivity in the ne pacific. Geophys. Res. Lett. 42, 428-431. doi: 10.1002/2014GL062634

Yu, L., Jin, X., and Weller, R. A. (2008). Multidecade Global Flux Datasets from the Objectively Analyzed Air-sea Fluxes (OAFlux) Project: Latent and Sensible Heat Fluxes, Ocean Evaporation, and Related Surface Meteorological Variables. Technical Report OA-2008-01, Woods Hole Oceanographic Institution, Woods Hole, MA.

Yu, L., and Weller, R. A. (2007). Objectively analyzed air-sea heat fluxes for the global ice-free oceans (1981-2005). Bull. Am. Meteorol. Soc. 88:527. doi: 10.1175/BAMS-88-4-527

Zaba, K. D., and Rudnick, D. L. (2016). The 2014-2015 warming anomaly in the Southern California Current system observed by underwater gliders. Geophys. Res. Lett. 43, 1241-1248. doi: 10.1002/2015GL067550

Zaba, K. D., Rudnick, D. L., Cornuelle, B. D., Gopalakrishnan, G., and Mazloff, M. R. (2018). Annual and interannual variability in the California current system: comparison of an ocean state estimate with a network of underwater gliders. J. Phys. Oceanogr. 48, 2965-2988. doi: 10.1175/JPO-D-180037.1

Conflict of Interest Statement: The authors declare that the research was conducted in the absence of any commercial or financial relationships that could be construed as a potential conflict of interest.

Copyright $\odot 2019$ Fewings and Brown. This is an open-access article distributed under the terms of the Creative Commons Attribution License (CC BY). The use, distribution or reproduction in other forums is permitted, provided the original author(s) and the copyright owner(s) are credited and that the original publication in this journal is cited, in accordance with accepted academic practice. No use distribution or reproduction is permitted which does not comply with these terms. 